Brit. J. prev. soc. Med. (1975), 29, 262-266

\title{
Primary schoolboys: image of self and smoker
}

\author{
J. MARTIN BLAND, BEULAH R. BEWLEY, AND ISOBEL DAY \\ Department of Community Medicine, St Thomas's Hospital Medical School, London
}

\begin{abstract}
Bland, J. M., Bewley, B. R., and Day, I. (1975). British Journal of Preventive and Social Medicine, 29, 262-266. Primary schoolboys: image of self and smoker. The way primary schoolboys see themselves and also see young smokers, may have implications for health education. In this paper a comparison is made between the self-images of 229 primary schoolboys and their images of a young person who smokes. The two images were very different, both for smokers and non-smokers, although the difference for smokers was smaller. It appears that children of this age who smoke do not see themselves as 'smokers', and may not relate the health education they receive on this subject to themselves.
\end{abstract}

Health education is potentially one of the more effective available methods of improving health, but it is a complex and unpredictable process. This is perhaps particularly so in the area of smoking.

Children start to smoke at an early age, and an increase in respiratory symptoms associated with this has been reported elsewhere (Holland and Elliott, 1968; Bewley, Halil, and Snaith, 1973). The long-term health consequences are well known. Health education efforts directed against smoking have not produced encouraging results (Holland and Elliott, 1968; Jeffreys, Norman-Taylor, and Griffiths, 1967). A better understanding of how children see smoking by others and themselves may help in the development of better preventive techniques.

As part of his study of secondary schoolboys, Bynner (1969) asked the boys to rate their images of themselves and of a smoker on a semantic differential scale. He found that self-image and smoker-image were much closer for smokers than for non-smokers. In this paper a description is given of a similar comparison among primary schoolboys.

\section{MeTHOD}

In March 1971, 7115 schoolchildren aged 10 to $11 \frac{1}{2}$ years, who were attending primary school in the administrative county of Derbyshire, completed a self-administered questionnaire about their smoking and respiratory symptoms. The methods and results of this survey have been reported elsewhere (Bewley et al. 1973). A sample of these children, stratified by smoking habit, was asked to complete a second, more detailed questionnaire in July 1971. For the stratification, the children were divided into four groups according to their smoking. A heavy smoker was defined as a child who reported smoking more than one cigarette a day, a light smoker as a child who smoked less than one cigarette a day but at least one a week, an experimental smoker as one who had smoked, but was smoking less than one a week, and a non-smoker as one who had never smoked. The 33 heavy smokers (29 boys and four girls) identified in the first stage were included in the sample. Altogether 67 light smokers were chosen at random. These 100 smokers were matched for sex, school class, and age (within six months) with 100 experimental smokers and 100 nonsmokers.

The second questionnaire was self-administered. The children were again asked about their smoking, and further questions were asked about smoking by members of the household and friends, and attitudes towards smoking. The results of these questions and the details of the method have been reported elsewhere (Bewley, Bland, and Harris, 1974). The children were also asked to tick as many as they wished of 16 words or phrases which they felt described themselves. The same 16 words were 
presented again in a different order, and the children were asked to tick those which described a young person who smokes cigarettes.

\section{RESULTS}

The analysis is based on boys only, as there were too few girls to provide meaningful results. A total of 229 boys completed the questionnaire, the remaining five having left the area or being absent from school at the time of the study.

The percentages of boys marking each item on the self-image scale are shown in Table I. There were significant differences between the groups for six items. More smokers than non-smokers saw themselves as 'tough', 'trouble-maker', 'good at sport', and 'foolish'. However, the majority of smokers did not see themselves in this way, 'foolish' being chosen by only $25 \%$ of smokers and 'troublemaker' by $35 \%$. More non-smokers than smokers saw themselves as 'friendly' and 'sensible'. The differences were small, and on the whole the pattern was similar in the four groups. The eight descriptions most frequently chosen by boys in each group were 'friendly', 'good at sport', 'sensible', 'good at school work', 'tough', 'easy going', 'good looking', and 'nervous', except that the non-smokers did not include 'tough' but substituted 'popular'.

The percentages of boys marking each item for a young person who smokes cigarettes are shown in Table II. There were three items which showed significant differences between the groups. Fewer smokers than non-smokers saw the smoker as a 'trouble-maker'. More of them saw the smoker as 'friendly' and 'clever' although these terms were chosen by only $31 \%$ and $24 \%$ respectively of the heavy smokers, and less often by the other groups. Again, the first eight items were similar in the four groups. These were, in order of frequency, 'foolish', 'trouble-maker', 'careless', 'tough', 'untidy', 'lazy', 'nervous', and 'easy going'. Among the heavy smokers, 'trouble-maker' was replaced by 'friendly' and among the light smokers 'good looking' was ranked seventh, 'lazy' and 'easy going' both being ranked eighth equal with 'good at sport'. For all groups, three items, 'tough', 'nervous', and 'easy going', were included in the first eight items for the images of both self and smoker.

Across all the four groups, the two images studied, of self and of smoker, are strikingly different.

TABLE I

IMAGE OF SELF: PERCENTAGE OF BOYS TICKING EACH ITEM

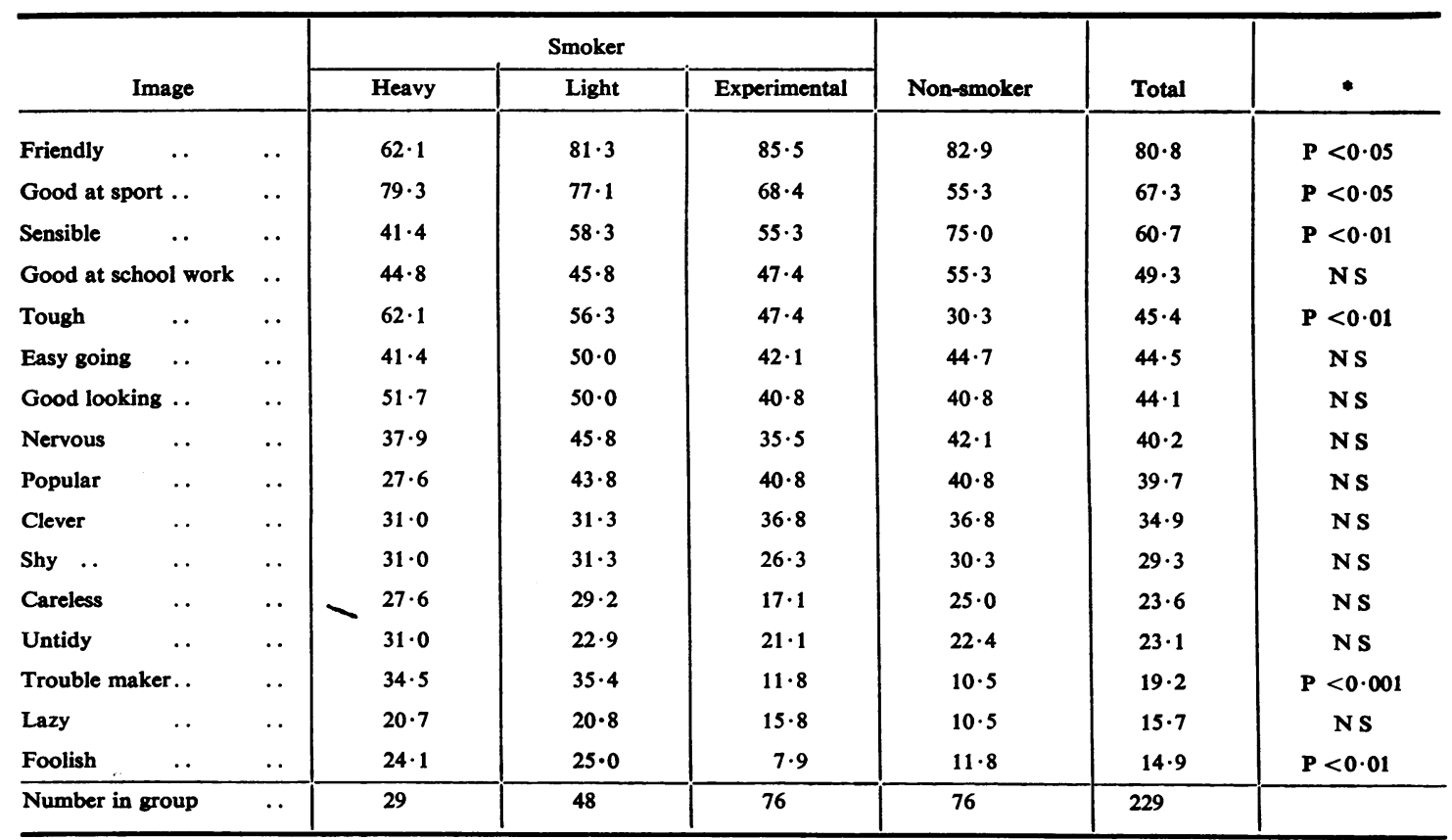

* Significance of $\chi^{2}$ test for difference between groups. Columns have been combined where neceseary 
TABLE II

IMAGE OF A YOUNG PERSON WHO SMOKES: PERCENTAGE OF BOYS TICKING EACH ITEM

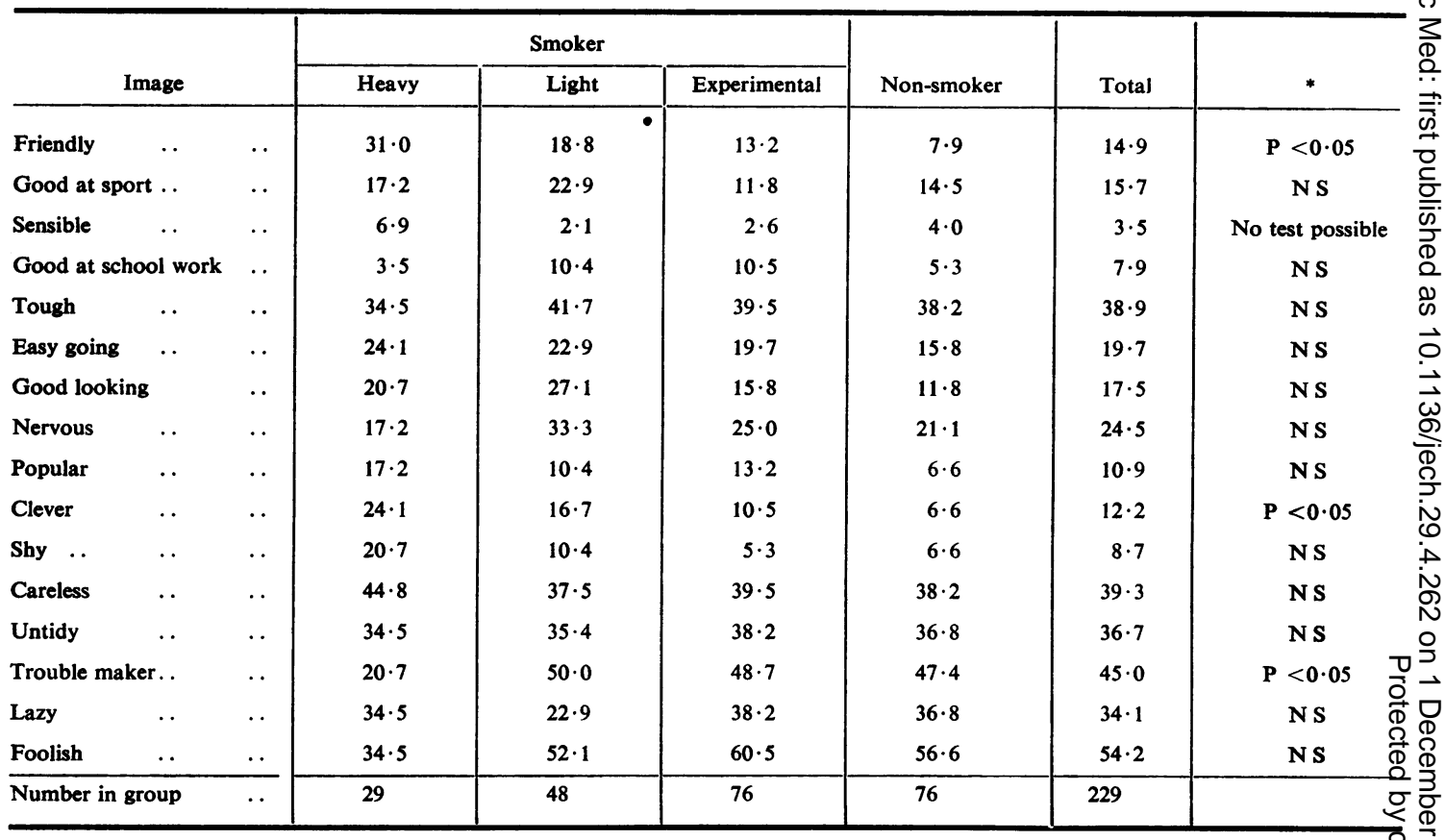

* Significance of $\chi^{2}$ test for differences between group. Columns have been combined where necessary

Some of the differences between the groups in the frequency with which particular items were chosen may have arisen because boys in different groups ticked with different frequencies. The mean number of ticks for each group in the image of self and the smoker showed no appreciable differences between the four groups (Table III).

The 16 items were also ranked according to the frequency with which they were chosen by each group, first as the image of self, and then as the image of the smoker (Table IV). The two rankings for each group were compared using Kendall's rank correlation coefficient (Kendall, 1970). This is also shown in Table IV, together with a test of significance using an approximate standard normal

TABLE III

MEAN NUMBER OF ITEMS SELECTED ON EACH SCALE FOR EACH GROUP

\begin{tabular}{c|c|c|c|c}
\hline \multirow{2}{*}{ Image } & \multicolumn{4}{c}{ Smokers } \\
\cline { 2 - 5 } \cline { 3 - 4 } Of self & Heavy & Light & Experimental & Non-smokers \\
\hline smoker & 6.5 & 7.0 & 6.0 & 6.1 \\
& 3.9 & 4.1 & 3.9 & 3.5 \\
\hline
\end{tabular}

variate. For each group of boys, the correlationt was negative, significantly for the non-smokers and for the experimental smokers, but not for the light or heavy smokers. There was a gradient in the correlations, the largest negative correlation being among the non-smokers, and the smallest being among the heavy smokers. Thus within each group, image of self and image of smoker were different, but among the smokers this difference was less marked.

\section{Discussion}

These data have a number of difficulties in interpretation. The boys may not have described themselves as they really saw themselves, but rather as they would like to be, or to appear. It is possible that the image they gave of a young person who smokes cigarettes was the way they actually saw the young smoker, or the image that they assumed $N^{\circ}$ would be acceptable to adults. As in the case of any $N$ study setting out to investigate attitudes and $N$ opinions, it is difficult to see how such a 'social desirability' effect can be removed, and these ambiguities resolved. However, although other interpretations are possible, we have interpreted $\stackrel{\mathscr{Q}}{\rightarrow}$ 
Primary schoolboys: image of self and smoker

TABLE IV

RANK ORDERS OF ITEMS IN IMAGE SCALE

\begin{tabular}{|c|c|c|c|c|c|c|c|c|c|c|c|c|}
\hline \multirow{3}{*}{\multicolumn{2}{|c|}{ Image }} & & \multirow{2}{*}{\multicolumn{2}{|c|}{$\frac{\text { Heavy Smokers }}{\text { Image of }}$}} & \multirow{2}{*}{\multicolumn{2}{|c|}{$\frac{\text { Light Smokers }}{\text { Image of }}$}} & \multirow{2}{*}{\multicolumn{2}{|c|}{$\frac{\text { Experimenters }}{\text { Image of }}$}} & \multirow{2}{*}{\multicolumn{2}{|c|}{$\frac{\text { Non-smokers }}{\text { Image of }}$}} & \multirow{2}{*}{\multicolumn{2}{|c|}{$\frac{\text { Totals }}{\text { Image of }}$}} \\
\hline & & & & & & & & & & & & \\
\hline & & & Self & Smoker & Self & Smoker & Self & Smoker & Self & Smoker & Self & Smoker \\
\hline Friendly & . & $\cdots$ & $2 \cdot 5$ & 6 & 1 & 11 & 1 & $10 \cdot 5$ & 1 & 11 & 1 & 11 \\
\hline Good at s & sport & $\cdots$ & 1 & 13 & 2 & 9 & 2 & 12 & $3 \cdot 5$ & 9 & 2 & 10 \\
\hline Sensible & $\cdots$ & $\cdots$ & $6 \cdot 5$ & 15 & 3 & 16 & 3 & 16 & 2 & 16 & 3 & 16 \\
\hline \multicolumn{3}{|c|}{ Good at school work } & 5 & 16 & $7 \cdot 5$ & 14 & $4 \cdot 5$ & $13 \cdot 5$ & $3 \cdot 5$ & 15 & 4 & 15 \\
\hline Tough & $\cdots$ & $\cdots$ & $2 \cdot 5$ & $3 \cdot 5$ & 4 & 3 & $4 \cdot 5$ & $3 \cdot 5$ & $10 \cdot 5$ & $3 \cdot 5$ & 5 & 4 \\
\hline Easy goin & & $\cdots$ & $6 \cdot 5$ & $7 \cdot 5$ & $5 \cdot 5$ & 9 & 6 & 8 & 5 & 8 & 6 & 8 \\
\hline Good loo & king & $\cdots$ & 4 & 10 & $5 \cdot 5$ & 7 & $7 \cdot 5$ & 9 & $7 \cdot 5$ & 10 & 7 & 9 \\
\hline Nervous & . & $\ldots$ & 8 & 13 & $7 \cdot 5$ & 6 & 10 & 7 & 6 & 7 & 8 & 7 \\
\hline Popular & . & . & $13 \cdot 5$ & 13 & 9 & 14 & $7 \cdot 5$ & $10 \cdot 5$ & $7 \cdot 5$ & 13 & 9 & 13 \\
\hline Clever & . & . & 11 & $7 \cdot 5$ & $11 \cdot 5$ & 12 & 9 & $13 \cdot 5$ & 9 & 13 & 10 & 12 \\
\hline Shy & . & . & 11 & 10 & $11 \cdot 5$ & 14 & 11 & 15 & $10 \cdot 5$ & 13 & 11 & 14 \\
\hline Careless & . & $\cdots$ & $13 \cdot 5$ & 1 & 13 & 4 & 13 & $3 \cdot 5$ & 12 & $3 \cdot 5$ & 12 & 3 \\
\hline Untidy & . & . & 11 & $3 \cdot 5$ & 15 & 5 & 12 & $5 \cdot 5$ & 13 & $5 \cdot 5$ & 13 & 5 \\
\hline Trouble $\mathbf{n}$ & maker & . & 9 & 10 & 10 & 2 & 15 & 2 & $15 \cdot 5$ & 2 & 14 & 2 \\
\hline Lazy & . & $\cdots$ & 16 & $3 \cdot 5$ & 16 & 9 & 14 & $5 \cdot 5$ & $15 \cdot 5$ & $5 \cdot 5$ & 15 & 6 \\
\hline Foolish & . & $\cdots$ & 15 & $3 \cdot 5$ & 14 & 1 & 16 & 1 & 14 & 1 & 16 & 1 \\
\hline \multicolumn{3}{|c|}{$\begin{array}{l}\text { Kendall's rank } \\
\text { correlation coefficient }\end{array}$} & \multicolumn{2}{|c|}{$-0 \cdot 30$} & \multicolumn{2}{|c|}{$-0 \cdot 22$} & \multicolumn{2}{|c|}{-0.47} & \multicolumn{2}{|c|}{-0.53} & \multicolumn{2}{|c|}{-0.43} \\
\hline $\mathbf{z}$ & $\cdots$ & $\cdots$ & $1 \cdot 5$ & $\mathbf{N} \mathbf{S}$ & $1 \cdot$ & N S & $2 \cdot 57$ & 0.05 & $2 \cdot 82$ & $<0.01$ & $2 \cdot 39$ & $<0.05$ \\
\hline
\end{tabular}

the data as the representation of the boys' true images of self and smoker.

These data suggest that in the early stages of taking up smoking, children do not identify themselves in the same way as they identify a smoker. The image of a smoker is of a boy who is foolish, a trouble-maker, careless, untidy, and tough. Their image of themselves is of someone friendly, sensible, good at sport and school work, and tough. The image of self is opposed to the image of the smoker. Despite this, those who smoke view the smoker in a more favourable light than does the non-smoker.

Two of the three items which showed frequency differences in the smoker image also showed differences in the self-image. Fewer smokers than non-smokers saw the smokers as a 'trouble-maker', but more smokers saw themselves as trouble-makers. More of the smokers saw the smoker as friendly, but few saw themselves as friendly. Differences on this item 'friendly' may possibly be explained by assuming that some children smoke in order to acquire friendship. However, it is difficult to find any comparable explanation for the differences on the item 'trouble-maker'.
It is hard to compare our findings with those of Bynner. We were dealing with a younger age group, and were not using precisely the same items or techniques, and we unfortunately did not follow Bynner in requesting the image of a non-smoker. Our finding that 'tough' was seen as a characteristic of the smoker, and that non-smokers were less likely to see themselves as 'tough', agrees with Bynner's finding among secondary schoolboys. In general, however, the differences between our groups were small, the separation being much less than that found by Bynner. This may have been because the boys were younger, marked differences between groups not yet having emerged.

The overall impression given by these data is that these boys did not see themselves as smokers. This is true even of those who said that they were smoking every day. They saw the young person who smokes as being very different from themselves. In a previous paper (Bewley et al., 1974), we gave the results of a series of questions on these boys' attitudes to smoking. Most of the boys in each group agreed that it was a bad idea for children to smoke, that it 
was a waste of money, and that children did it to show off. Less than half in any group thought smoking was enjoyable.

Perhaps in the light of this, we can interpret the data as showing that at this age boys who smoke do not see themselves as 'the smoker' at whom health education is directed. If this is so, health educators are faced with a serious problem-how to discourage children from smoking cigarettes if they do not recognize themselves as smokers?

This work was supported by the Department of Health and Social Security and by a grant from the Medical Research Council. We wish to thank the staffs of Derbyshire Health and Education Departments, Professor W. W. Holland, Dr A. H. Snaith and Mr T. Halil for their help and advice.

Requests for reprints: J. M. Bland, MSc, DIC, Department of Community Medicine, St Thomas's Hospital Medical School, London SE1 7EH.

\section{REFERENCES}

Bewley, B. R., Bland, J. M., and Harris, R. (1974). Factors associated with the starting of cigarette smoking by primary schoolchildren. Brit. J. prev. soc. Med., 28, 37.

Halil, T., and SNaIth, A. H. (1973). Smoking by primary schoolchildren: prevalence and associated respiratory symptoms. Brit. J. prev. soc. Med., 27, 150.

BynNer, J. M. (1969). The Young Smoker. Government Social Survey. HMSO, London.

Holland, W. W. and Elliotr, A. (1968). Cigarette smoking, respiratory symptoms and anti-smoking propaganda. Lancet, 1, 41.

Jefreys, M., Norman-Taylor, W., and Griffiths, G. (1967). Long term results of an anti-smoking educational campaign. Med. Offr, 117, 93.

Kendall, M. G. (1970). Rank Correlation Methods, 4th ed. Griffin, London. 